\title{
Topography and Microhardness Changes of Nanofilled Resin Composite Restorations Submitted to Different Finishing and Polishing Systems and Erosive Challenge
}

\author{
Fernanda Michel Tavares Canto ${ }^{1}$, Adílis Kalina Alexandria ${ }^{1}$, Marcela Baraúna Magno ${ }^{10}$, \\ Eduardo Moreira da Silva² ${ }^{\circledR}$, Lucianne Cople Maia1(10
}

\begin{abstract}
${ }^{1}$ Department of Pediatric Dentistry and Orthodontics, Federal University of Rio de Janeiro, Rio de Janeiro, RJ, Brazil. ${ }^{2}$ Analytical Laboratory of Restorative Biomaterials, Fluminense Federal University, Rio de Janeiro, RJ, Brazil.
\end{abstract}

Author to whom correspondence should be addressed: Lucianne Cople Maia, Rua Rodolpho Paulo Rocco, 325, Cidade Universitária, Rio de Janeiro, RJ, Brazil. 21941-913. Phone: +55 21 3938-2098. E-mail: rorefa@terra.com.br.

Academic Editors: Alessandro Leite Cavalcanti and Wilton Wilney Nascimento Padilha

Received: 10 April 2019 / Accepted: 20 September 2019 / Published: 25 October 2019

How to cite this article: Canto FMT, Alexandria AK, Magno MB, Silva EM, Maia LC. Topography and microhardness changes of nanofilled resin composite restorations submitted to different finishing and polishing systems and erosive challenge. Pesqui Bras Odontopediatria Clín Integr. 2020; 20:e4812. https://doi.org/10.1590/pboci.2020.003

\begin{abstract}
Objective: To evaluate the topography and microhardness of composite resin restorations submitted to different finishing and polishing systems before and after erosive challenge. Material and Methods: Thirty standardized cavities prepared in enamel-dentin blocks of bovine incisors were restored with Z350 composite resin, and randomly distributed into three groups $(\mathrm{n}=10)$ according to the finishing and polishing systems: G1 = Soflex 4 steps, G2 = Soflex Spiral 2 steps and G3 = PoGo (single step). The specimens were half protected with nail varnish and submitted to five immersions in Pepsi Twist ${ }^{\circledR}$, for 10 minutes each, five times/day during six consecutive days. The initial and final challenge surface microhardness (SMHinitial and SMHfinal) of the composite resin was evaluated and the percentage of SMH loss (\%SMHL) was calculated. After protection removal, the topographic change linear $(\mathrm{Ra})$ and volumetric $(\mathrm{Sa})$ roughness was evaluated in initial and final areas by using $3 \mathrm{D}$ non-contact optical profilometry and scanning electron microscopy (SEM). Data were analyzed by paired Student's t-test, Kruskal-Wallis test, and by ANOVA and Tukey's test. Results: There was significant intra-group \%SMHL in composite resin $(p<0.05)$. Differences among groups in \%SMHL, Ra/Sa in resin composite were not observed ( $\mathrm{p}>0.05)$. SEM images revealed structural changes between the initial and final surfaces for all groups. Conclusion: The three types of finishing and polishing systems had a similar influence on \%SMHL, Ra and Sa in the nanofilled composite resin.
\end{abstract}

Keywords: Tooth Erosion; Dental Materials; Composite Resins; Dental Polishing. 


\section{Introduction}

Dental erosion is a localized, chronic, pathological, and painless loss of mineralized dental tissue due to the exposition to acids, without direct bacterial involvement [1]. This can be influenced by Intrinsic factors such as diseases that cause regurgitation of gastric juices or decreasing of the salivary flow, as well as by extrinsic factors linked to diet (consumption of fruits and acid drinks) harmful environments (chemical industries and swimming pools treated with chlorine), and some medicines (aspirin, vitamin $\mathrm{C}$ and Hydrochloric acid) [2]. Unfortunately, changes in the lifestyle of the individuals have significantly increased the consumption of acidic beverages, which contributes to the onset of dental erosion [3]. This is a clinical matter of concern.

Even with the clinical insertion like ceramic laminates, the use of resin restorations is still very common because of its cost-effectiveness and its more conservative preparation. In the field of restorative dentistry, it has been proved that the action of acidic beverages on resin composites may cause changes in their microhardness due to the disruption of the interactions between the monomers present in their polymeric matrixes [4].

Generally, the last step in a clinical protocol to build up resin composite restorations is the finishing and polishing, which aims to reduce the coarse contours and the grooves left by the hand instruments, thereby resulting in a smoother and shiny surface, and to create a anatomic form as closely as possible to that of the natural tooth [5]. An effective finishing and polishing step also contributes to the reduction on biofilm accumulation, thereby increasing the composite's resistance to dye impregnation and wear, and improving its optical properties as well [6,7].

With the intent of reducing costs and clinical time, new polishing systems with a reduction in the number of steps, have been proposed. Among them are the Soflex four stages. This is flexible discs with decreasing granulations of color-coded polyurethane coated aluminum oxide (from dark to light) [8]. Soflex Spiral two stages are composed of two turns, one to soften and remove possible scratches in the restorations, and another to create a very smooth and high gloss polish. In addition, there is the single-stage PoGo system, which is represented by a single disc/flame tip based on silicon and diamond microparticles [9].

Therefore, the objective of this study was to evaluate the topography and microhardness of composite resin restorations submitted to different finishing and polishing systems before and after erosive challenge, since there is an increasingly early insertion of acidic beverages into the diet, and preserving the structure of the restorative material for a longer period is of the utmost importance. The null hypothesis was that irrespective of finishing and polishing systems, there would be no difference in topographic and microhardness of the nanofilled resin composite when submitted to the same erosion pattern.

\section{Material and Methods}

Specimen Preparation

Thirty enamel-dentin blocks with $6 \times 6 \times 2 \mathrm{~mm}$ obtained from bovine teeth without cracks or enamel defects were stored in a $2 \%$ formaldehyde aqueous solution for disinfection until the experiment beginning. The blocks were cut with two diamond discs (Extec Corp., Enfield, Connecticut, United States) fixed in parallel in an Isomet low-speed saw cutting machine (Buehler, Lake Bluff, Illinois, USA) (Figure 1A). The blocks had their enamel surfaces flatted in a polishing machine (Arotec, São Paulo, Brazil) with 600, 800 and 1200-grit SiC paper (3M ESPE, St Paul, MN, USA) (Figure 1B). The enamel blocks were randomly allocated into three groups $(n=10)$ according to the future nanofilled finishing and polishing systems used (Figure $1 \mathrm{C}$ ). 
A cavity, $1.8 \mathrm{~mm}$ in diameter and $1.8 \mathrm{~mm}$ depth, was prepared in each enamel block by using a \#1016 diamond bur in a high-speed handpiece under wet-cooling, to simulate the finishing and polishing system in the oral cavity (Figure 1C). The cavities were filled with Z350 nanofilled resin composite (3M ESPE, St Paul, MN, USA), according to the following protocol: 1) etching with 35\% phosphoric acid (Scotchbond Etchant, $3 \mathrm{M}$ ESPE, St Paul, MN, USA) for $15 \mathrm{~s}$, water rinsing and drying; 2) active application of Universal Single Bond (3M ESPE, St Paul, MN, USA) adhesive system, followed by photoactivation for $20 \mathrm{~s}$ and 3 ) insertion of composite resin in two increments of $1 \mathrm{~mm}$ each and photoactivated for $20 \mathrm{~s}$ (Figure 1D). Before the photoactivation of the last increment of Z350 resin composite, the cavities were covered with a polyester strip and pressed with a glass plate. After removing the glass plate and the polyester strip, the resin composite was additionally photoactivated for $20 \mathrm{~s}$ (Figures 1 D, E, F, G, H). The restorations were finished and polished with the finishing and polishing systems mounted in a low-speed handpiece, applying circular movements without water spray and for 20 s each step: G1 = Soflex Pop on 4 steps (3M ESPE, St Paul, MN,USA); G2 = Soflex spiral 2 steps (3M ESPE, St Paul, MN, USA) and G3 = PoGo 1 step (Dentsply, Rio de Janeiro, RJ, Brazil). Afterward, the specimens were ultrasonically cleaned with distilled and deionized water (Milli- $Q^{\circledR}, M^{2}$ KGaA, Darmstadt, Germany) for $40 \mathrm{~s}$ and dried (Figure 1 I1, I2, I3). The SMHinitial Knoop of each restoration was obtained with three indentations spaced $100 \mu \mathrm{m}$ apart from each other, at a $10 \mathrm{~g}$ load and $5 \mathrm{~s}$ dwell time.

\section{Erosive Challenge}

Before the erosive challenge, half of each specimen (initial area), including enamel and resin composite, was covered with an acid-resistant varnish (nail varnish) (Figure $1 \mathrm{~K}$ ). Then, the specimens were submitted to an erosive challenge, as recommended by some authors [10,11]. Demineralization through immersion and gentle shaking for $10 \mathrm{~min}$ in $30 \mathrm{~mL}$ of Pepsi Twist (carbonated water, sugar, cola nut extract, concentrated lemon juice, caffeine, caramel coloring, sodium benzoate, sodium citrate, citric acid and phosphoric acid, AMBEV, Jundiaí, São Paulo, SP, Brazil), $\mathrm{pH}=3.2$; rinsing with Mili-Q water for 30 s; and remineralization through immersion for $1 \mathrm{~h}$ in $30 \mathrm{~mL}$ of artificial saliva $(0.2205 \mathrm{~g} / \mathrm{L}$ calcium chloride, $0.1224 \mathrm{~g} / \mathrm{L}$ potassium phosphate, $11.182 \mathrm{~g} / \mathrm{L}$ potassium chloride, $12.114 \mathrm{~g} / \mathrm{L}$ Tris and $500 \mu \mathrm{L} / \mathrm{L}$ Fluorine) [12]. This erosive cycle was performed five times/day, with an interval of one hour from each other, over a period of six consecutive days. After the sixth day daily cycle, the samples were maintained in artificial saliva and the nail varnish was removal (Figure $1 \mathrm{~L} 1, \mathrm{~L} 2, \mathrm{M})$.

\section{Final Microhardness}

After the erosive challenge, the SMHfinal of resin composite was reevaluated exactly as previously described. The percentage of SMH loss (\% SMHL) was calculated using the following equation: \%SMHL = SMHinitial - SMHfinal / SMHinitial X100, where SMHinitial is the microhardness before the erosive challenge and SMHfinal is the microhardness after the erosive challenge [13] (Figure $1 \mathrm{~N}$ ).

\section{Scanning Electron Microscopy (SEM) Analysis}

Two samples for each group, randomly selected, were fixed on stubs with double-faced carbon tape,), and analyzed using a SEM (JSM-5410LV, JEOL, Tokyo, Japan). SEM images were taken at 1500X, including the initial and final areas (Figure 1 O). 


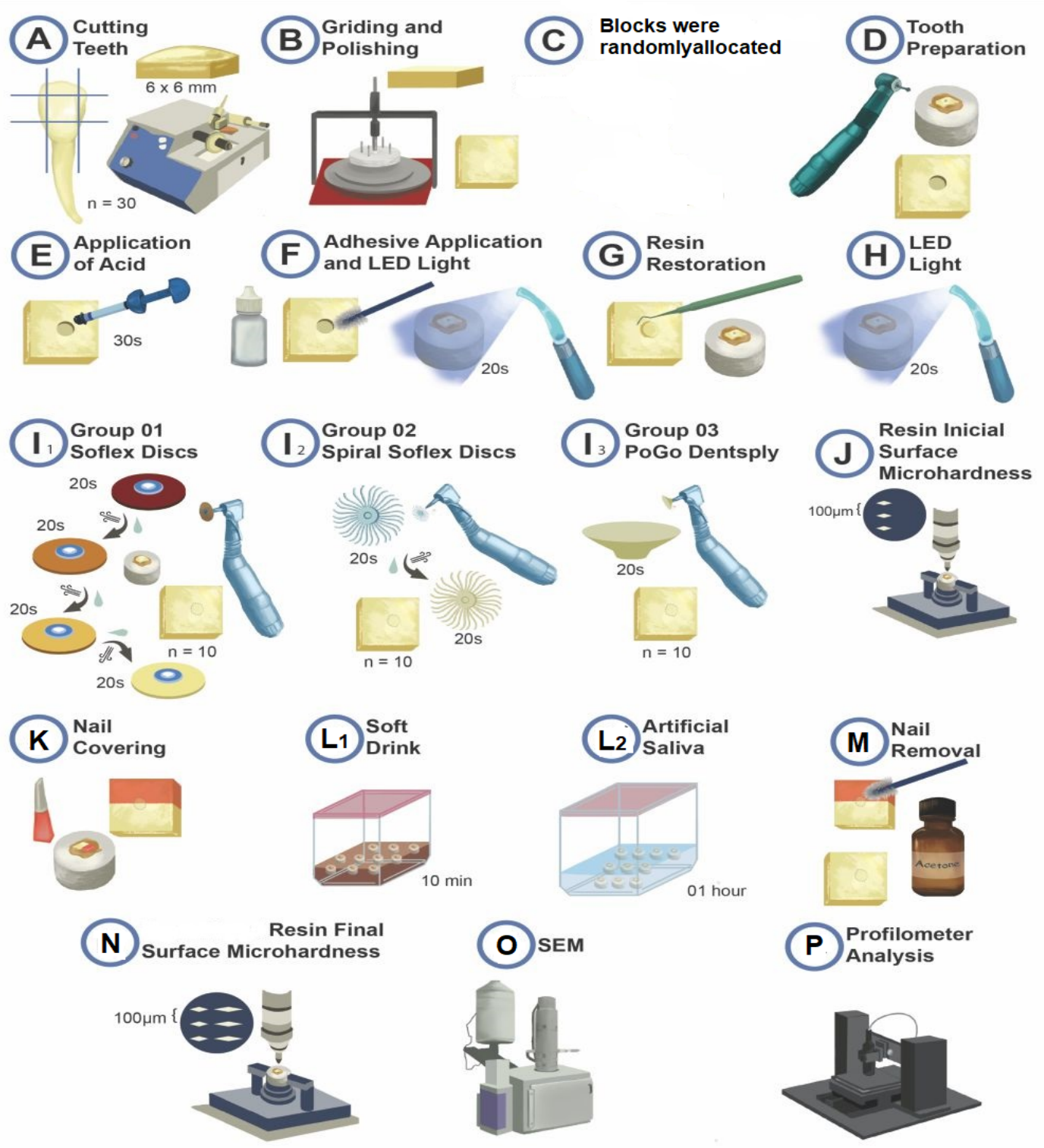

Figure 1. Schematic drawing of methodological steps.

3D Non-Contact Profilometry Analysis

The 3D non-contact profilometry technique was used to determine: i) surface roughness (linear and volumetric), and ii) structure loss (SL) after treatment [14].

After final microhardness evaluation, the acid-resistant nail varnish was removed from all specimens, and both areas (initial and final) from enamel and composite resin were evaluated through a $3 \mathrm{D}$ non-contact chromatic confocal optical profilometry (Nanovea PS50 Optical, NANOVEA Inc., Irvine, CA, United States). From each specimen, an area of $2.0 \mathrm{~mm}$ x $1.0 \mathrm{~mm}$, including initial and final areas, in resin, was captured using a chromatic confocal sensor with a white light axial source, scan velocity of $2 \mu / \mathrm{s}$ and a refraction index of 10,000. For linear surface roughness $(\mathrm{Ra})$, three linear horizontal measurements $(500 \mu \mathrm{m})$ were taken in the initial and final areas in composite resin. The average of these three measurements was used to determine Rainitial and Rafinal (linear surface roughness in the initial and final areas, respectively). The Ra value for all groups was calculated as: $\mathrm{Ra}=$ Rafinal - Rainitial. For volumetric surface roughness (Sa) (ISO 25178), three scan areas $(250 \mu \mathrm{m} \times 250 \mu \mathrm{m})$ were acquired in the initial and final areas in composite resin and the average 
was used to determine Sainitial and Safinal (volumetric surface roughness in the initial and final areas, respectively). As for $\mathrm{Ra}$, the Sa value for all groups was calculated as $\mathrm{Sa}=$ Safinal - Sainitial. The Ra and $\mathrm{Sa}$ values were used to compare the composite resin topography before (initial) and after (final) exposure to erosive challenge.

Three profile measurements $(1 \mathrm{~mm})$ were taken involving the initial and final areas and the depth in height $(\mu \mathrm{m})$ between these two areas, for composite resin represented the SL, with the average expressed in $\mu \mathrm{m}$ (Figure $1 \mathrm{P})$.

\section{Statistical Analysis}

For each dependent variable, the normal distribution of errors was checked using Shapiro-Wilk's test. Based on this preliminary analysis, the intragroup (initial vs. final) difference of the SMH was analyzed by paired Student's t-test. The \%SMHL and the Sa data were analyzed using Kruskal-Wallis, followed by MannWhitney. The Ra and SL data were analyzed using one-way ANOVA and Tukey's post hoc test. SPSS software version 22.0 (IBM, New York, New York, United States) was used for all statistical analyses. The significance level was set at $5 \%(\mathrm{p}<0.05)$. SEM results were analyzed descriptively.

\section{Results}

In the non-contact 3D profile analysis, there was no difference among the three types of finishing and polishing systems, considering the Ra $(\mathrm{p}=0.303)$ and Sa values $(\mathrm{p}=0.121)$, and SL $(\mathrm{p}=0.098)$ observed $($ Table 1$)$. In Figure 2, it is possible to observe the $3 \mathrm{D}$ images generated by the profilometry analysis; these images have shown the initial and final topographic characteristics of the sample.

Table 1. Linear roughness (Ra), volumetric roughness (Sa) and structure loss (SL) of nanofilled composite resin submitted to erosive challenge.

\begin{tabular}{cccc} 
Groups & \multicolumn{3}{c}{ Composite Resin } \\
& Ra & Sa & SL \\
\hline G1 (Soflex 4 Steps) & $0.91(0.52)$ & $6.14(-0.02)$ & $31.12(16.48)$ \\
G2 (Soflex 2 Steps) & $0.79(0.28)$ & $14.48(0.74)$ & $37.93(21.62)$ \\
G3 (PoGo) & $0.91(0.30)$ & $12.36(0.23)$ & $48.73(19.35)$ \\
p-value & 0.303 & 0.121 & 0.098 \\
\hline
\end{tabular}

A

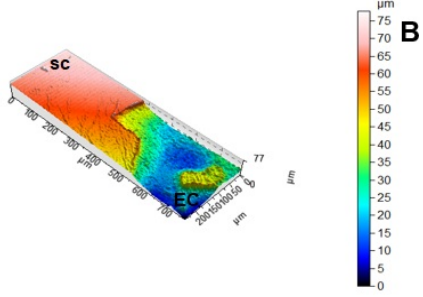

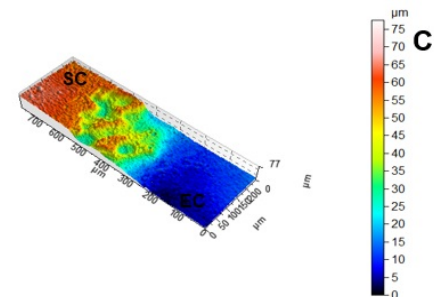

Figure 2. 3D profilometry scheme representation of samples before and after erosive challenge. (A) G1 = Z350 resin with Soflex polishing 4 steps, (B) G2= Z350 resin with 2-step Soflex polishing and (C) G3= Resin Z350 with polishing PoGo 1 step. SC: sound composite, EC: eroded composite.

Results indicated that, after erosive challenge, the finishing and polishing systems used did not influence in \%SMHL of composite resin in an intergroup comparison $(p=0.618)$. However, there was a 
significant statistical difference in microhardness values when comparing initial and final areas of composite restoration finishing and polishing systems (G1 p=0.04, G2 p=0.05 and G3 p=0.01) (Table 2).

Table 2. Surface microhardness (SMH) nanofilled composite resin submitted to erosive challenge.

\begin{tabular}{cccc} 
Groups & $\begin{array}{c}\text { SMH }_{\text {initial }} \text { Composite } \\
\text { Resin }\end{array}$ & $\begin{array}{c}\text { SMH }_{\text {final }} \text { Composite } \\
\text { Resin }\end{array}$ & $\begin{array}{c}\text { \%SMHL Composite } \\
\text { Resin }\end{array}$ \\
\hline G1 (Soflex 4 Steps) & $52.44(23.13)^{\mathrm{a}}$ & $38.40(16.86)^{\mathrm{b}}$ & $20.63(20.63)$ \\
G2 (Soflex 2 Steps) & $48.25(13.52)^{\mathrm{a}}$ & $35.32(13.01)^{\mathrm{b}}$ & $25.33(25.59)$ \\
G3 (PoGo) & $56.16(12.14)^{\mathrm{a}}$ & $39.06(8.18)^{\mathrm{b}}$ & $27.07(27.19)$ \\
\hline
\end{tabular}

Different letters represent statistical differences ( $\mathrm{p} \leq 0.05)$.

Imaging using SEM it is possible to verify structural differences (qualitative) in composite resin of each finishing and polishing systems G1 (Figure 3A), G2 (Figure 3B) and G3 (Figure 3C) before and after the cycle erosive. The resin composite polished with the 4 steps system (G1) (Figure 3A) demonstrated formation of cracks in the resinous matrix after erosion. The resin composite polished with Soflex Spiral 2 steps (G2) (Figure 3B) appeared more polished than G1 after erosion challenge, even in the presence of erosion islands. The resin composite polished with the 1 step system (G3) (Figure 3C) showed areas where particles have been removed, with a lower number of islands of erosion in relation to G2.

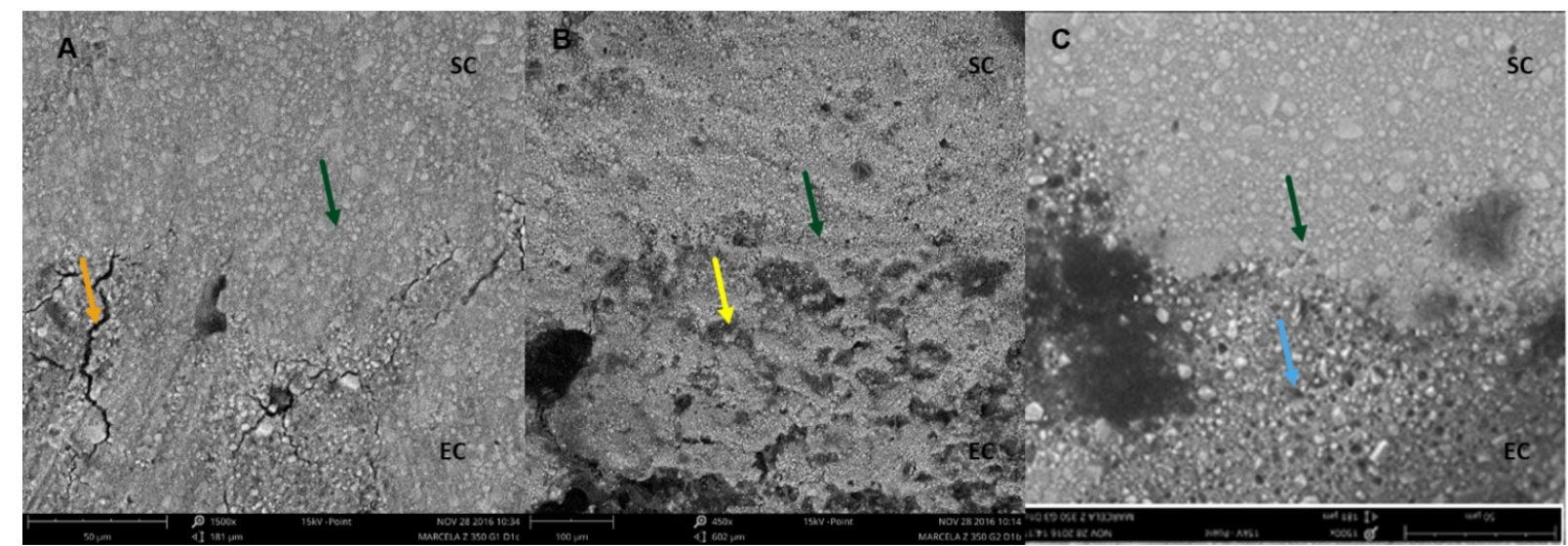

Figure 3. Surface SEM images of composite samples before and after erosive challenge at 1500X (Photomicrographs of the interface SC: sound composite, EC: eroded composite). (A) G1= Z350 resin with Soflex polishing 4 steps, (B) G2= Z350 resin with 2-step Soflex polishing and (C) G3= Resin Z350 with polishing PoGo 1 step. A green arrow indicates division: sound part of the eroded part, orange arrow indicates islands of erosion in the composite resin and blue arrow indicates the removal of cargo particles following erosion.

\section{Discussion}

The aim of this study was to evaluate a nanofilled composite resin polished with different finishing and polishing systems (Soflex 4 steps, Soflex Spiral 2 steps and PoGo) in relation to microhardness and alterations in the material surface, following a sample being submitted to erosive challenge. Restorative materials can suffer degradation that generates surface roughness when exposed to acidic substances and this is an important factor in bacterial adhesion [15]. Therefore, the adequate finishing and polishing of the dental restorations are critical to ensure lower adhesion of microorganisms, as well as to improve the aesthetics and the longevity of the restoration [16].

The acidic liquid (Pepsi Twist ${ }^{\circledR}$ ) and the time protocol (5 cycles per day during 6 days) used in this study were based on previous studies [11,13] that also evaluated erosion in dental materials, as well as the 
present study. In addition, the use of a high intensity erosive challenge protocol was chosen in the present study to closely match the clinical situation, since the constant and intense consumption of soft drinks has been noticed by most of the world population [17].

Our study showed a great loss of resin structure when using Pepsi, showing a significant step between the initial and final areas. Showing that the loss of restorative material due to erosion is worrying, considering the time the cycling was performed.

In the present study, there was an increase in the surface roughness of restorative material after erosive cycling. This occurred because erosive substances could modify the topography of restorative materials surfaces, which has been shown in previous studies that reported the polymers presented a decrease and weakening between the hydrogen bonds, leading of the material due to less interaction between the molecules of the polymer. Thus, leaving irregularities on its surface may cause an increase in its surface and volumetric roughness $[18,19]$, as observed in table 1 of the present study.

It has been previously shown that the PoGo finishing and polishing systems generated a greater surface roughness of the Z250 resin when compared to the Soflex type, disagreeing with our results where no difference was observed between the groups. This may be explained because the Z250 resin is a micro-hybrid resin, and larger particles offer less protection on the resin matrix from a finishing and polishing process [20]. On the other hand, the results of a previous research [21] are in agreement with our study, since the authors also observed that PoGo and Soflex 4 steps did not present statistical differences of roughness in the analysis with profilometry using nano-composites as in our study.

In addition, it was observed in MEV that the single-step finishing and polishing system (G3) demonstrated an increased exposure of resin matrix after erosive challenge. Probably this polishing system was not able to flatten the charge particles, this way, irregular particles were exposed and were displaced, as was reported in previous studies that related the reduction of surface microhardness in resins to the loss of the filler particles, the degradation of the bonding agent (silane) and the resin matrix [22].

Therefore, further research is required to better understand the exact mechanism of the progression of changes in restorative materials submitted to different finishing and polishing systems against such challenges in the complex oral environment. In addition, an enamel cavity was done in order to simulate a dental restoration.

In summary, the findings in the present study suggest that the type of finishing and polishing systems does not influence the loss of hardness of nanofilled resins and irrespective of the number of steps and finishing and polishing systems system used, there will be structural alterations in the restorative material. It is important to emphasize that the results of the present study should be interpreted with caution. Clinically, the erosion process may occur in the presence of biofilm, which may influence the erosion-degradation process of enamel and dental materials. There were no differences between the types of finishing and polishing systems and the results are important to justify the application of the fastest steps in pediatric dentistry for example, where the less time in the chair positively influences the behavior of children, in addition to its low cost when compared to the other types. All groups had topographic changes in composite resin after erosive challenge, but without significant differences between the groups. However, structural alterations were observed in 3D profilometry and SEM images. So, the three types of finishing and polishing systems had a similar influence on \%SMHL, Ra and Sa in the nanofilled composite resin. 


\section{Conclusion}

The three types of finishing and polishing systems had a similar influence on \%SMHL, Ra and Sa in the nanofilled composite resin.

\section{Authors' Contributions}

\begin{tabular}{|c|c|c|}
\hline FMTC & (iD) $0000-0002-7058-5724$ & $\begin{array}{l}\text { Conceptualization, Methodology, Investigation, Formal Analysis, Writing - } \\
\text { Original Draft Preparation and Writing - Review and Editing. }\end{array}$ \\
\hline AKA & (iD) $0000-0003-4774-1204$ & Formal Analysis and Writing - Review and Editing. \\
\hline MBM & (iD) $0000-0003-3618-190 \mathrm{X}$ & Investigation, Formal Analysis and Writing - Review and Editing. \\
\hline EMS & (iD) $0000-0001-7963-2956$ & Formal Analysis and Writing - Review and Editing. \\
\hline $\mathrm{LCM}$ & (iD) $0000-0003-1026-9401$ & Conceptualization and Writing - Review and Editing. \\
\hline
\end{tabular}

\section{Financial Support}

This study was supported by the CAPES (Coordenação de Aperfeiçoamento de Pessoal de Nível Superior- Brasil) - Finance Code 001 and FAPERJ (Fundação Carlos Chagas Filho de Amparo à Pesquisa do Estado do Rio de Janeiro) (Grant No. E26/202.924/2017).

\section{Conflict of Interest}

All authors declare that there are no conflicts of interests related to the present article.

\section{References}

[1] Ganss C. Definition of erosion and links to tooth wear. Monogr Oral Sci 2006; 20:9-16. https://doi.org/10.1159/000093344

[2] Ten Gate J, Imfeld T. Dental erosion, summary. Eur J Oral Sci 1996; 104(2):241-4. https://doi.org/10.1111/j.1600-0722.1996.tbo0073.x

[3] Karda B, Jindal R, Mahajan S, Sandhu S, Sharma S, Kaur R. To analyse the erosive potential of commercially available drinks on dental enamel and various tooth coloured restorative materials - an in-vitro study. J Clin Diagn Res JCDR 2016; 10(5):ZC117-21. https://doi.org/10.7860/JCDR/2016/16956.7841

[4] Guedes APA, Oliveira-Reis B, Catelan A, Suzuki TYU, Briso ALF, Santos PHD. Mechanical and surface properties analysis of restorative materials submitted to erosive challenges in situ. Eur J Dent 2018; 12(4):559-65. https://doi.org/10.4103/ejd.ejd_188_18

[5] Da Costa J, Ferracane J, Paravina RD, Mazur RF, Roeder L. The effect of different polishing systems on surface roughness and gloss of various resin composites. J Esthet Restor Dent 2007; 19(4):214-24. https://doi.org/10.1111/j.1708-8240.2007.00104.x

[6] Aykent F, Yondem I, Ozyesil AG, Gunal SK, Avunduk MC, Ozkan S. Effect of different finishing techniques for restorative materials on surface roughness and bacterial adhesion. J Prosthet Dent 2010; 103(4):221-7. https://doi.org/10.1016/So022-3913(10)60034-0

[7] Bollen CM, Lambrechts P, Quirynen M. Comparison of surface roughness of oral hard materials to the threshold surface roughness for bacterial plaque retention: a review of the literature. Dent Mater 1997; 13(4):258-69. https://doi.org/10.1016/S0109-5641(97)80038-3

[8] Antonio AG, Iorio NL, Pierro VS, Candreva MS, Farah A, Dos Santos KR, et al. Inhibitory properties of Coffea canephora extract against oral bacteria and its effect on demineralisation of deciduous teeth. Arch Oral Biol 2011; 56(6):556-64. https://doi.org/10.1016/j.archoralbio.2010.12.001

[9] Turkun LS, Turkun M. The effect of one-step polishing system on the surface roughness of three esthetic resin composite materials. Oper Dent 2004; 29(2):203-11.

[10] Soares LES, De Carvalho Filho AC. Protective effect of fluoride varnish and fluoride gel on enamel erosion: roughness, SEM-EDS, and $\mu$-EDXRF studies. Microsc Res Tech 2015; 78(3):240-8. https://doi.org/10.1002/jemt.22467

[11] Soares LE, Soares AL, De Oliveira R, Nahórny S. The effects of acid erosion and remineralization on enamel and three different dental materials: FT-Raman spectroscopy and scanning electron microscopy analysis. Microsc Res Tech 2016; 79(7):646-56. https://doi.org/10.1002/jemt.22679

[12] Queiroz, CS, Hara AT, Paes Leme AF, Cury JA. pH-cycling models to evaluate the effect of low fluoride dentifrice on enamel de- and remineralization. Braz Dent J 2008;19(1):2 1-7. https://doi.org/10.1590/s0103-64402008000100004 
[13] Nassur C, Alexandria AK, Pomarico L, de Sousa VP, Cabral LM, Maia LC. Characterization of a new TiF4 and $\beta$ cyclodextrin inclusion complex and its in vitro evaluation on inhibiting enamel demineralization. Arch Oral Biol 2013; 58(3):239-47. https://doi.org/10.1016/j.archoralbio.2012.11.001

[14] Alexandria AK, Vieira TI, Pithon MM, da Silva Fidalgo TK, Fonseca-Gonçalves A, Valença AM, et al. In vitro enamel erosion and abrasion-inhibiting effect of different fluoride varnishes. Arch Oral Biol 2017; 77:39-43. https://doi.org/10.1016/j.archoralbio.2017.01.010

[15] Park JW, Song CW, Jung JH, Ahn SJ, Ferracane JL. The effects of surface roughness of composite resin on biofilm formation of Streptococcus mutans in the presence of saliva. Oper Dent 2012; 37(5):532-9. https://doi.org/10.2341/11-371-L

[16] Nair VS, Sainudeen S, Padmanabhan P, Vijayashankar L, Sujathan U, Pillai R. Three-dimensional evaluation of surface roughness of resin composites after finishing and polishing. J Conserv Dent 2016; 19(1):91-5. https://doi.org/10.4103/0972-0707.173208

[17] Vartanian, LR, Schwartz, MB, Brownell KD. Effects of soft drink consumption on nutrition and health: a systematic review and meta-analysis. Am J Public Health 2007; 97(4):667-75. https://doi.org/10.2 105/AJPH.2005.083782

[18] Lussi A, Schlueter N, Rakhmatullina E, Ganss C. Dental erosion - an overview with emphasis on chemical and histopathological aspects. Caries Res 2011; 45(Suppl. 1):2-12. https://doi.org/10.1159/000325915

[19] Dawes C. What is the critical pH and why does a tooth dissolve in acid? J Can Dent Assoc 2003; 69(11):722-5.

[20] Yadav RD, Raisingani D, Jindal D, Mathur R. A comparative analysis of different finishing and polishing devices on nanofilled, microfilled, and hybrid composite: a scanning electron microscopy and profilometric study. Int J Clin Pediatr Dent 2016; 9(3):201-8. https://doi.org/10.5005/jp-journals-10005-1364

[21] Erdemir U, Sancakli HS, Yildiz E. The effect of one-step and multi-step polishing systems on the surface roughness and microhardness of novel resin composites. Eur J Dent 2012; 6(2):198-205.

[22] Ergücü Z, Türkün L, Aladag A. Color stability of nanocomposites polished with one-step systems. Oper Dent 2008; 33(4):413-20. https://doi.org/10.2341/07-107

[23] Watanabe T, Miyazaki M, Takamizawa T, Kurokawa H, Rikuta A, Ando S. Influence of polishing duration on surface roughness of resin composites. J Oral Sci 2005; 47(1):21-5. https://doi.org/10.2334/josnusd.47.2 1 